\title{
Collaborative model of care between Orthopaedics and allied healthcare professionals trial (CONNACT) - a feasibility study in patients with knee osteoarthritis using a mixed method approach
}

\author{
Bryan Yijia Tan ${ }^{1,2^{*}}$ (D) Benjamin Tze Keong Ding ${ }^{3}$, Michelle Jessica Pereira ${ }^{4}$, Soren Thorgaard Skou ${ }^{5,6}$,
} Julian Thumboo ${ }^{7}$ and Josip $\mathrm{Car}^{2}$

\begin{abstract}
Background: Osteoarthritis is a leading cause of global disability resulting in significant morbidity and cost to the healthcare system. Current guidelines recommend lifestyle changes such exercises and weight loss as first line treatment prior to surgical consideration. Our current model of care is inefficient with suboptimal allied health intervention for effective behaviour changes. A 12-week community based, individualized, multidisciplinary new model of care for knee osteoarthritis was developed in light of current deficiencies.

Methods: The primary aim of this study was to determine the feasibility of a full randomized controlled trial evaluating this new model of care using pre-defined progression criteria. The secondary aim was to optimize the intervention and study design through a process evaluation. A pilot exploratory, parallel arm, single blinded randomized trial design using a mixed method approach was utilized. Progression criteria for a full trial including key domains of patient recruitment and retention, outcome measure acceptability and improvement, adverse events were developed. The primary outcome measure was the Knee Injury and Osteoarthritis Outcome Score (KOOS) at baseline and 12-weeks. Secondary outcomes included quality of life, functional and psychological assessments. Semi-structured interviews were conducted with the patients at 12-weeks.

\footnotetext{
* Correspondence: btanyj@hotmail.com

'Department of Orthopaedic Surgery, Woodlands Health Campus, National

Healthcare Group, Singapore, Singapore

${ }^{2}$ Lee Kong Chian School of Medicine, Nanyang Technological University,

Singapore, Singapore

Full list of author information is available at the end of the article
}

C The Author(s). 2020 Open Access This article is licensed under a Creative Commons Attribution 4.0 International License, which permits use, sharing, adaptation, distribution and reproduction in any medium or format, as long as you give appropriate credit to the original author(s) and the source, provide a link to the Creative Commons licence, and indicate if changes were made. The images or other third party material in this article are included in the article's Creative Commons licence, unless indicated otherwise in a credit line to the material. If material is not included in the article's Creative Commons licence and your intended use is not permitted by statutory regulation or exceeds the permitted use, you will need to obtain permission directly from the copyright holder. To view a copy of this licence, visit http://creativecommons.org/licenses/by/4.0/. The Creative Commons Public Domain Dedication waiver (http://creativecommons.org/publicdomain/zero/1.0/) applies to the data made available in this article, unless otherwise stated in a credit line to the data. 
(Continued from previous page)

Results: 20 patients (3 males, 17 females) were randomized (10 intervention, 10 control). Intervention arm patients reported better improvements in their knee function, quality of life, psychological outcome, dietary improvement and weight loss compared to the control arm at 12-weeks. Semi-structured interviews revealed several themes pertaining to feasibility and intervention optimization. 5 out of the 6 progression criteria's domains were met (recruitment criteria not met).

Conclusion: This pilot has demonstrated the feasibility of a full randomized control trial investigating the potential effectiveness of the new proposed model of care for knee osteoarthritis using pre-defined progression criteria and process evaluation. Results from the qualitative study were used to modify and improve the intervention content, delivery model and study design for a large effectiveness-implementation hybrid randomized control trial that is currently underway.

Trial registration: Retrospectively registered on 18 January 2019 at http://clinicaltrial.gov ID: NCT03809975.

Keywords: Knee, Osteoarthritis, Model of care, Pilot, Feasibility. Mixed methods

\section{Background}

With a rapidly aging population, Musculoskeletal (MSK) disorders account for the largest cause of disability around the world. In particular, osteoarthritis (OA) is currently the 11th highest global cause of disability [1]. International guidelines are consistent in their recommendations for individualized lifestyle changes, especially exercise and weight loss programs to manage knee $\mathrm{OA}$ and recommend a stepwise approach where surgery is considered when non-surgical treatment fails $[2,3]$. Yet, international studies report that at least $60 \%$ of patients from established healthcare systems around the world such as Australia, Canada and the US are not receiving optimal non-surgical treatment [4-6].

There remains suboptimal use of non-surgical treatment such as allied health interventions (e.g. delivered by physiotherapist and psychologists) to support effective lifestyle and behaviour changes in most models of care [7]. As a result, surgery is at present often a result not from a failure of non-surgical treatment but failure of the healthcare system to provide adequate and efficient conservative treatment. The literature suggests that at least a quarter of knee arthroplasty could have been avoided through optimal non-surgical treatment ${ }^{8}$. In the United States, it is anticipated that knee arthroplasty rates will rise by $673 \%$ between 2005 to 2030 [8]. In Australia similarly, it is anticipated there will be a $276 \%$ increase between 2013 to 2030 [9]. While knee arthroplasty surgery has been shown to be an effective option for knee OA, it is not without risks, complications or downsides. Firstly, it is expensive [10]. Secondly, complications while uncommon can still occur and certain complications such a popliteal artery damage or deep infection can have devastating consequences [11]. Thirdly, as knee arthroplasty have a limited lifespan, the earlier surgery is done the higher the likelihood of a revision surgery being required in the future [12]. Fourthly, up to $25 \%$ of patients remain unsatisfied [13] and up to $34 \%$ of patients have unfavourable long-term pain outcomes post-surgery [14].

There is an urgent need for new Models of Care (MoC) for OA by optimizing evidence-based nonsurgical treatments to deliver value-based care. Combination treatments have shown promise in literature with several trials demonstrating effectiveness mostly in exercise and nutritional combination interventions $[15,16]$. More recent studies have looked at the effectiveness of other combinations including self-management education programs and psychological support [17, 18]. Very few studies have looked at incorporating multiple components in a complex intervention [19]. The Collaborative Model of Care between Orthopaedics and Allied Healthcare Professionals (CONNACT) model of care is a complex intervention that was developed in to meet this gap in literature. CONNACT is a community-based, multidisciplinary (Orthopaedics, Physiotherapy, Dietetics, Psychology and Social Work) 12-week program that uniquely uses an individualized approach based on a triaging criterion to tailor the treatment to each patient in line with the "right care, right time, right team, right place" philosophy of any successful model of care.

\section{Methodology}

\section{Aim and study design}

The primary aim of this study was to determine the feasibility of a full randomized controlled trial (RCT) using pre-defined progression criteria. The secondary aim was to optimize the intervention and study design through a process evaluation in preparation for a full RCT. The RCT will test the clinical effectiveness of the community-based, individualized, multidisciplinary model of care for knee OA (CONNACT) compared to usual care.

A pilot exploratory, parallel arm, single blinded randomized trial design was used for the proof of concept, feasibility study based on the conceptual framework 
developed by Eldridge et al. [20]. Guidelines based on the OA Research Society International (OARSI) clinical trials recommendations were used in the design of the study [21]. It was conducted as a single centre pragmatic pilot randomized trial. Ethics approval was obtained through the Institution Review Board prior to the conduct of the study. The Consolidated Standards of Reporting Trials (CONSORT) checklist for pilot studies was used to ensure comprehensive reporting of this pilot study [22].

\section{Participants and recruitment process}

Patients who were referred by a primary healthcare or emergency medicine doctor to the Outpatient clinic at the Department of Orthopaedic Surgery at Tan Tock Seng Hospital, a tertiary referral centre in Singapore with a suspected diagnosis of knee OA were screened based on the inclusion and exclusion criteria presented in Table 1. All referral letters were screened based on electronic medical records for inclusion and exclusion criteria. Patients who were eligible were invited to attend a recruitment clinic where they were assessed by the study team and invited to participate in the study if they met all the inclusion and exclusion criteria. Recruitment clinics were carried out in the Tan Tock Seng Hospital Specialist Outpatient Clinic.

The choice of inclusion and exclusion criterion were based on similar studies [19] with the primary intent of identifying patients with primary knee $\mathrm{OA}$ who were sufficiently disabled from the condition both from functional and radiological perspective but would likely benefit from an intervention (medical fitness, ability to follow study protocol and community ambulator).

\section{Intervention - CONNACT model of care}

$\mathrm{A} \mathrm{MoC}$ is an evidence informed policy or framework that outlines the optimal manner in which a condition should be managed by addressing the principles of care and how it should be implemented in the local setting. "Right care, delivered at the right time, by the right team, in the right place, with the right resources" is the ideal end state for any $\mathrm{MoC}$ [26].

The CONNACT MoC was developed starting with a throughout literature search on the best practices in knee osteoarthritis care [3, 27], a review of successful programs [7], international collaborations with the Good Life with Osteoarthritis in Denmark (GLA:D) program from Denmark [28] and Osteoarthritis Chronic Care Program (OACCP) from Australia [29]. Collaborators from the GLA:D and OACCP shared best practices from their programs and gave expert advice on program development. Adapting it to our local context was done through engagement with local experts from the different speciality groups.

The CONNACT MoC principles are highlighted below based on the key goals of any $\mathrm{MoC}$.

1. Right Care - Fundamental paradigm shift by moving from an acute episodic type treatment generally associated with $\mathrm{OA}$ to a chronic disease model of care [30] with a focus on patient empowerment, behavioural modification in a multidisciplinary team community based approach grounded in best practices. The intervention consisted for 4 main components.
a. Clinical Assessment and Education
b. Exercise therapy
c. Nutrition and Dietetics
d. Psychological Support

Each component was designed to enhance the other components synergistically e.g. behavioural change strategies taught during the psychological class is used to improve compliance to exercise and diet modification.

2. Right Time - Individualized care for each patient based on a triaging criterion e.g. nutrition class for

Table 1 Inclusion and Exclusion Criteria

\begin{tabular}{|c|c|}
\hline Inclusion Criteria (all 4 must be present) & Exclusion Criteria \\
\hline $\begin{array}{l}\text { National Institute of Health and Care Excellence (NICE) clinical } \\
\text { criteria for knee OA [23] } \\
\text { 1. Age } \geq 45 \text { years old and } \\
\text { 2. Has activity related knee pain and } \\
\text { 3. Has either no morning knee-related stiffness or morning } \\
\text { stiffness than last no longer than } 30 \text { min }\end{array}$ & Alternative diagnosis to knee OA e.g. Referred pain from the spine or hip \\
\hline $\begin{array}{l}\text { Radiographic severity of knee OA, Kellgren-Lawrence Score [24] } \\
>1\end{array}$ & Secondary arthritis e.g. inflammatory, post-traumatic \\
\hline Knee Injury and OA Outcome Score [25] $\left(\mathrm{KOOS}_{4}\right) \leq 75$ & Inability to comply with study protocol e.g. cognitive impairment \\
\hline \multirow[t]{3}{*}{ Community ambulator with or without walking aid } & Previous knee arthroplasty \\
\hline & Wheelchair bound patients \\
\hline & $\begin{array}{l}\text { Medical condition that will medically interfere with study involvement e.g. } \\
\text { decompensated heart failure, stroke, end stage renal failure }\end{array}$ \\
\hline
\end{tabular}


obese patients to ensure timely and appropriate care for patients

3. Right Team - Multidisciplinary team consisting of Orthopaedic surgeons, Physiotherapists, Dieticians, Psychologists, Social workers

4. Right Place - Community based to bringing care closer to the patients and remove the disease stigma associated with a hospital environment. The intervention was conducted at Ang Mo Kio St Luke Eldercare Centre, a community-based rehabilitation centre with exercise facilities.

Triaging Criterion were developed to individualize treatment from the onset. All patients would receive the education and physical exercise components. A BMI cut off was used as a criterion for dietician intervention. In light of the significant impact of psychological conditions (anxiety, depression) and pain intensity and interference in predicting outcomes in osteoarthritis patients [31, 32], Patient Health Questionnaire-4 (PHQ-4) [33] a 4-item screening assessment for depression and anxiety and Pain Intensity, Enjoyment of life and General Activity (PEG) [34], an 3-item assessment of pain intensity interference derived from the Brief Pain Inventory (BPI) [35] was selected as appropriate triaging tools in addition to outcome measures.

Intervention will be delivered in a group based format as group-based interventions have been shown to be more effective compared to individual interventions in promoting physical activity through cohesion and peer support [36]. Numbers for the class were kept between 8 and 10 participants per class to ensure good participant facilitator ratio and optimize group dynamics.

Details for each intervention component including the triaging criteria, healthcare professional delivering the intervention and treatment principles are summarized in Table 2.

\section{Usual care}

Usual care constituted a referral to the outpatient physiotherapist at the tertiary hospital where patients were seen 1-2 weeks post referral. The physiotherapist would conduct an assessment and recommend a variety of lifestyle modifications and exercise therapy. The type of exercises and number of physiotherapy sessions were at the discretion of the patient and the physiotherapist.

\section{Outcomes measures}

The primary outcome measure used was the Knee Injury and Osteoarthritis Outcome Score $\left(\mathrm{KOOS}_{4}\right)$. KOOS contains 5 domains of questions namely symptoms, pain, function (daily living), function (sports, recreational activities) and quality of life. Consistent with other studies with similar population of elderly patients with knee OA, the function (sports, recreational activities) subscale were deemed to be less relevant for this population and the remaining 4 domains were combined to form a composite score [19]. The KOOS score has been validated in Singapore [42]. Secondary outcomes included KOOS individual subscales, quality of life scoring, functional assessment, diet and psychological related outcomes. Outcome measures were collected at baseline and 12weeks. Any adverse events were collected through the study during all follow up visits including data collection and intervention visits. Table 3 summarizes all the outcome measures. Baseline data on the patient demographics, socioeconomical status, Co-morbidities and functional status (Charlson comorbidity index [43], Barthel Index for Activities of Daily Living [44]) were collected as well.

The EQ-5D-5L value set that has been validated for the Singapore population using a time trade-off method was used to calculate utility values [50]. The choice of functional assessments was based on the recommended OARSI performance test for functional testing in OA [51]. Modification to the original Food Frequency

Table 2 Intervention Summary

\begin{tabular}{|c|c|c|c|c|}
\hline $\begin{array}{l}\text { Intervention } \\
\text { Component }\end{array}$ & Criteria to receive intervention & $\begin{array}{l}\text { Healthcare } \\
\text { Professional }\end{array}$ & Treatment Principles & Delivery \\
\hline Exercise Therapy & All patients & Physiotherapist & $\begin{array}{l}\text { American College of Sports Medicine (ACSM) [37] } \\
\text { Neuromuscular Exercise (NEMEX) [28] guidelines }\end{array}$ & $\begin{array}{l}\text { Group sessions } \\
\times 6\end{array}$ \\
\hline $\begin{array}{l}\text { Clinical } \\
\text { Assessment and } \\
\text { Education }\end{array}$ & All patients & $\begin{array}{l}\text { Orthopaedic } \\
\text { Surgeon }\end{array}$ & $\begin{array}{l}\text { Clinical and Radiological Assessment } \\
\text { Pharmacological Intervention }\end{array}$ & $\begin{array}{l}\text { Group } \\
\text { Education } \\
\text { sessions } \times 2\end{array}$ \\
\hline $\begin{array}{l}\text { Dietetics and } \\
\text { Nutrition }\end{array}$ & $\mathrm{BMI}>23.5^{\mathrm{a}}$ & Dietician & $\begin{array}{l}\text { Dietary intervention to increase dietary related nutrition } \\
\text { knowledge and self-efficacy for effective weight loss [38] }\end{array}$ & $\begin{array}{l}\text { Group sessions } \\
\times 3\end{array}$ \\
\hline $\begin{array}{l}\text { Psychological } \\
\text { support }\end{array}$ & $\begin{array}{l}\text { Patient Health Questionnaire } 4 \\
(\mathrm{PHQ}-4)>5 \\
\text { or } \\
\text { Pain, Enjoyment, General } \\
\text { Activity Scale (PEG) > } 4 \text { on all } \\
\text { scales }\end{array}$ & $\begin{array}{l}\text { Psychologist } \\
\text { Medical Social } \\
\text { Worker }\end{array}$ & $\begin{array}{l}\text { Acceptance and Commitment Therapy }(\mathrm{ACT}) \text { principles [39, } \\
40] \\
\text { Pain Management Coping Strategies } \\
\text { Improving compliance to behavioural modifications }\end{array}$ & $\begin{array}{l}\text { Group sessions } \\
\times 3\end{array}$ \\
\hline
\end{tabular}

${ }^{\mathrm{a}}$ A lower cut off of BMI 23.5 is recommended for Asians [41] 
Table 3 Outcome Measures

\begin{tabular}{ll}
\hline Outcome Measure & Variables \\
\hline Baseline Measures & Demographics (Age, Gender) \\
& Socioeconomical status \\
& Medical Co-morbidities \\
& Functional status (Charlson comorbidity index [43], Barthel Index for Activities of Daily Living [44]) \\
& Knee Injury and Osteoarthritis Outcome Score (KOOS 4 ) [25] \\
Primary Outcome Measures & Knee Injury and Osteoarthritis Outcome (KOOS) subscales (pain, symptoms, function, quality of life) \\
Secondary Outcome Measures & Quality of Life EQ-5D-5L [45] \\
& Functional Assessment (30s chair stand, 10 m fast paced walk, stair climb, timed up-and-go) \\
& Body Mass Index (BMI) \\
& Modified Semi-Quantitative Food Frequency Questionnaire (FFQ) [46] \\
& Patient Health Questionnaire 4 (PHQ-4) [33] \\
& Pain, Enjoyment, General Activity Scale (PEG) [34] \\
& Acceptance and Action Questionnaire 2 (AAQ-II) [47] \\
Chronic Pain Acceptance Questionnaire 8 (CPAQ-8) [48] & Global Impression of Change (GIC) [49] \\
Adverse events
\end{tabular}

Questionnaire (FFQ) was performed to reduce the length to reduce questionnaire burden and adapt it based on local dietary practices. Scoring was developed based on the weightage of fat/sugar/fibre content of the particular food item based on the energy and nutrient composition reported by the Singapore Health Promotion Board (http://focus.hpb.gov.sg/eservices/ENCF/). Modified FFQ was only done for patients who had a $\mathrm{BMI}>23.5$.

\section{Progression criteria to decide whether to proceed with RCT}

Randomized Controlled Trials (RCT) are expensive, time consuming endeavours. Having robust progression criteria to a larger, definitive RCT based on pilot data is crucial to objectively determining if the pilot RCT should be developed into a larger, definitive RCT. Based on the guidelines and key considerations proposed by Avery and colleagues for developing and using progression criteria for internal pilot studies [52], progression criteria were developed by the study team (Table 4). The guide highlighted the elements of any pilot study that should be critically evaluated including patient recruitment, intervention adherence, adverse outcome rates and outcome assessment burden. In addition, these progression criteria were recommended to be predetermined to ensure critical evaluation in establishing RCT viability.

In assessing patient recruitment, the guide recommended the use of a rates per unit time. Considering the average time for grant funding (2-3 years) and the average sample size (100-150 patients) used by similar studies $[19,53]$, a target of 30 patients in 3 months was set to ensure that sufficient recruitment would be achievable during the main RCT assuming a consistent recruitment strategy to the pilot study was followed. A low threshold for adverse outcome was set with a target of no serious care-related adverse event. A serious care-related adverse event was defined as an event related to the treatment that was limb or life threatening or resulted in

Table 4 Progression Criteria for $\mathrm{RCT}$

\begin{tabular}{|c|c|c|c|}
\hline Domain & Proceed with RCT & $\begin{array}{l}\text { Proceed, but changes to the protocol } \\
\text { need to be discussed }\end{array}$ & $\begin{array}{l}\text { Do not proceed with main trial unless } \\
\text { the problem can be solved }\end{array}$ \\
\hline Recruitment & $\begin{array}{l}\text { Recruitment of } 30 \text { participants with OA } \\
\text { within } 3 \text { months }\end{array}$ & $\begin{array}{l}\text { Recruitment of } 30 \text { participants with OA } \\
\text { within 3-6 months }\end{array}$ & $\begin{array}{l}30 \text { participants with } \mathrm{OA} \text { are not recruited } \\
\text { within } 6 \text { months }\end{array}$ \\
\hline Retention & $\begin{array}{l}\text { At least } 75 \% \text { retention of participants } \\
\text { through follow up }\end{array}$ & $\begin{array}{l}\text { At least } 50 \% \text { retention of participants } \\
\text { through follow up }\end{array}$ & $\begin{array}{l}\text { Less than } 50 \% \text { retention of participants } \\
\text { through follow up }\end{array}$ \\
\hline $\begin{array}{l}\text { Completion of } \\
\text { Intervention }\end{array}$ & $\begin{array}{l}\text { At least } 75 \% \text { complete more than half of } \\
\text { the intervention }\end{array}$ & $\begin{array}{l}\text { At least } 50 \% \text { complete more than half of } \\
\text { the intervention }\end{array}$ & $\begin{array}{l}\text { Less than } 50 \% \text { complete more than half } \\
\text { of the intervention }\end{array}$ \\
\hline $\begin{array}{l}\text { Outcome Measures } \\
\text { Acceptability }\end{array}$ & $\begin{array}{l}\text { At least } 80 \% \text { of participants do not find } \\
\text { the outcomes so burdensome that they } \\
\text { would not participate in the study again }\end{array}$ & $\begin{array}{l}\text { At least } 70 \% \text { of participants do not find } \\
\text { the outcomes so burdensome that they } \\
\text { would not participate in the study again }\end{array}$ & $\begin{array}{l}\text { Less than } 70 \% \text { of participants do not find } \\
\text { the outcomes so burdensome that they } \\
\text { would not participate in the study again }\end{array}$ \\
\hline $\begin{array}{l}\text { Function and/or } \\
\text { Quality of Life } \\
\text { Improvement }\end{array}$ & $\begin{array}{l}\text { Improvements in function and/or quality } \\
\text { of life found by at least } 50 \% \text { of the } \\
\text { participants }\end{array}$ & $\begin{array}{l}\text { Improvements in function and/or quality } \\
\text { of life found by at least } 25 \% \text { of the } \\
\text { participants }\end{array}$ & $\begin{array}{l}\text { Improvements in function and/or quality } \\
\text { of life found by less than } 25 \% \text { of the } \\
\text { participants }\end{array}$ \\
\hline Adverse events & $\begin{array}{l}\text { No serious care-related adverse events } \\
\text { during follow up }\end{array}$ & $\begin{array}{l}\text { Less than five serious care-related ad- } \\
\text { verse events during follow up }\end{array}$ & $\begin{array}{l}\text { Five or more serious care-related adverse } \\
\text { events during follow up }\end{array}$ \\
\hline
\end{tabular}


hospitalization. Targets for completeness of intervention (75\%), retention $(75 \%)$ and outcome measures acceptability (80\%) were set to ensure that loss of follow-up or missing data would be kept to a minimum for the main trial. Completeness of intervention was defined as finishing more than half the intervention. Retention was the defined as the number of patients who completed the study including the final outcome measure. Outcome measure acceptability was defined as the numbers of patients do not find the outcomes so burdensome that they would not participate in the study again. Function or quality of life improvement targets were set at $50 \%$ to ensure intervention effectiveness. Improvement was defined a positive change in either functional or quality of life outcomes.

Avery et al. recommended the use of a red/amber/ green traffic light system instead of a simple stop/go basis. An amber light would indicate that a change in protocol is recommended before proceeding with the main RCT while a red light would indicate serious issues with the study and until those issues were resolves, proceeding to an RCT would not be recommended.

\section{Sample size}

Whitehead et al. proposed a method using the standardized effect size to estimate the sample size for a pilot randomized trial instead of using the rule of thumb method which ranged from 24 to 70 patient sample size [54]. Based on an estimated standardized effect size 0.5 reported by a systematic review and meta-regression analysis of RCTs for exercise based interventions for knee OA in pain and disability [55], assuming 90\% power and two-sided 5\% significance, 15 patients in each arm were recommended.

\section{Randomization and data collection}

Study data were collected and managed using REDCap electronic data capture tools $[56,57]$. Patients who consented to participate were randomized (1; 1 allocation ratio) between the intervention and usual care using a permuted block randomization method using block sizes of 4,6 and 8. The random allocation sequence was generated by an independent statistician and was kept concealed from the study team. Randomization was done using the REDCap randomization module and allocation was locked once assigned. Randomization was only performed after the patient was counselled fully about the study, had provided informed consent and baseline data was collected.

\section{Blinding}

Outcome measures were measured by blinded outcome assessors. The outcome assessors received training prior to study initiation to ensure good inter- and intra- observer reliability particularly for the functional outcome testing. Patients were instructed not to reveal their allocation to the outcome assessors.

\section{Statistical analysis}

The results were analysed using an intention-to-treat (ITT) principle. Data was entered and analysed using the IBM SPSS Statistical Software Version 25. The data was checked for completeness and consistency prior to analysis. Descriptive frequency analysis was used for baseline characteristics. For continuous variables, the mean and standard deviation were reported. For categorical variables, the frequencies and percentages were reported. In view of the sample size, independent hypothesis testing using non-parametric Mann Whitney U test to look for differences between intervention and control group. The median and interquartile range were presented with the corresponding $p$ values. The significance level was set at $5 \%$.

\section{Process evaluation}

Through purposive sampling, semi-structured interviews were conducted with the intervention arm patients at 12-weeks as part of the process evaluation. The Medical Research Council (MRC) has developed a set of guidelines for the conduct of process evaluations [58]. MRC recommends a basic framework for process evaluation with the emphasis being different at each stage of the study. In the pilot phase, the key is in understanding the feasibility and intervention design optimization. The interview guide and questions (Table 5) were based on the key emphasis on feasibility for a full RCT based on the proposed progression criteria above and intervention design optimization based on the MRC guidance.

The semi-structured interviews were conducted by a research assistant, TCY, who was involved with the patient recruitment and coordination of care. The potential bias the interviewer had on the patients as part of the study team was balanced by the fact that having journeyed with the patients, she had gained the trust of all the patients, most of them who were willing to share with her their personal problems. As a member of the study team but yet not a healthcare professional who delivered the intervention, patients were more open to share with her their honest opinions. In addition, having seen the entire 12-week process, she was in an ideal position to probe intelligently during the interview guided by the topic guide. Extensive hand written notes and quotes were noted down during the interview and the results were interpreted through a thematic analysis by a senior researcher (BTY) with qualitative experience. 
Table 5 Interview Topic Guide

\begin{tabular}{ll}
\hline Topic & Questions \\
\hline Intervention Design & Did you feel that you benefitted from the intervention? Why? \\
What specific part of the intervention did you find most useful? Why? & Did you find being in a group helpful or would you have preferred more individual attention? \\
& Do you have any suggestions on how we can make the program better? \\
& Were you able to complete the whole program? Were there external reasons that prevented your full participations? \\
Feasibility & Would you participate again in the program if given a chance? Would you recommend your friends to participate in \\
& the program? \\
& Did you find the outcome measures too burdensome to complete? Which ones?
\end{tabular}

\section{Results}

\section{Participants and baseline characteristics}

From late August to early November 2018, over a period of 3 months, a total of 20 patients were recruited (10 control and 10 intervention). Final follow up at 3 months were completed in February 2019. Control group patients were younger with a mean age of 59.6 years old with a distribution of 7 females and 3 males. The intervention arm patients had a mean age of 68.0 years old and was made up of all females. Baseline characteristics are presented in Table 6 and study flow in Fig. 1.

\section{Outcomes}

In terms of knee function scores and quality of life, there was a clear trend of the intervention arm patients having a higher $\mathrm{KOOS}_{4}$, KOOS symptoms/stiffness, KOOS quality of life, EQ-5D VAS. Psychological outcomes wise, there was a clear trend where the PEG was positively impacted to a greater extent at 12-weeks in the intervention group compared to the control group. This was the case of weight where intervention patients lost weight compared to the control arm where patients gained weight after 12-weeks. Functional outcomes were equivocal where the control arm demonstrated faster timed $10 \mathrm{~m}$ walk test and time up-and-go test and intervention arm patients demonstrating a higher 30s chair stand test. None of the results reached statistical significance. Table 7 summarises the outcome measures.

For all the patients with $\mathrm{BMI}>23.5$, all the patients in the intervention arm $(n=3)$ demonstrated positive change in their dietary habits based on the modified FFQ compared to the control arm $(n=7)$ where only $57.1 \%$ of patients demonstrated a positive change in their dietary habits after 12-weeks.

One patient in the intervention arm suffered adverse events. The patient developed concurrent back pain during the course of the program. It was ascertained that the patient had long standing low back pain which was exacerbated during the intervention. Assessment by an independent physiotherapist deemed that the exercises prescribed were unlikely to cause the exacerbation. The back exacerbation was treated successfully with physiotherapy and analgesia. One patient in the control arm who deteriorated was subsequently diagnosed with spontaneous osteonecrosis of the knee and underwent knee arthroplasty.

\section{Progression criteria results}

All domains except patient recruitment met progression criteria to proceed with the RCT (green light) based on the evaluation by the study team. Over a 3-month period, only 20 patients were recruited. Based on the pre-determined progression criteria, an allowance of 6 months was permissible to determine if the target of 30 patients was achievable distinguishing between the amber and red light. While recruitment of 30 patients over a 6-month period was potentially possible for this pilot study, such a recruitment rate was not feasible for the main trial in view of grant funding time restrictions and logistical considerations for the main trial that were not known during the conceptualization of the predetermined progression criteria. A decision was made to classify this as a red light prompting significant changes to be made to achieve a green light before the main trial could proceed. Table 8 summarizes the feasibility for full RCT based on the progression criteria.

\section{Process evaluation}

A total of 8 patients in the intervention arm were interviewed as part of the process evaluation. Two patients in the intervention arm declined to be interviewed.

The first focus was on intervention optimization. Several themes were identified. Firstly, for the exercise component, all the patients felt that it was beneficial. Three patients felt the number of sessions could be increased with an additional 2 sessions for greater benefit. Learning different exercises techniques and how to adapt them based on individual fitness and needs was a key benefit that patients reported. While patients recognized that it was beneficial to exercise, there was a realization that they were unlikely to return to normal function. This point was emphasized during the education and psychology sessions where an acceptance of the irreversible effects of aging was important while at the same 
Table 6 Baseline Characteristics

\begin{tabular}{|c|c|c|}
\hline & Control $(n=10)$ & Intervention $(n=10)$ \\
\hline Age (years), mean (SD) & $59.6(6.52)$ & $68.0(8.11)$ \\
\hline Women, n (\%) & $7(70 \%)$ & $10(100 \%)$ \\
\hline Weight (kg), mean (SD) & $68.34(13.97)$ & $60.15(8.18)$ \\
\hline \multicolumn{3}{|l|}{ Affected Knee Joint, n (\%) } \\
\hline Right & $4(40 \%)$ & $2(20 \%)$ \\
\hline Left & $3(30 \%)$ & $4(40 \%)$ \\
\hline Bilateral & $3(30 \%)$ & $4(40 \%)$ \\
\hline \multicolumn{3}{|c|}{ Radiographic knee OA severity (Kellgren-Lawrence), $\mathrm{n}(\%)^{\mathrm{a}}$} \\
\hline Grade 2 & $5(50 \%)$ & $2(20 \%)$ \\
\hline Grade 3 & $3(30 \%)$ & $7(70 \%)$ \\
\hline Grade 4 & $2(20 \%)$ & $1(10 \%)$ \\
\hline Barthel Index, mean (SD) & $19.7(0.48)$ & $19.5(0.53)$ \\
\hline \multicolumn{3}{|l|}{ Charlson Comorbidity Score, n (\%) } \\
\hline 0 & $6(60 \%)$ & $9(90 \%)$ \\
\hline 1 & $4(40 \%)$ & $1(10 \%)$ \\
\hline 2 or above & 0 & 0 \\
\hline \multicolumn{3}{|c|}{ Knee Injury and Osteoarthritis Outcome Score, mean ${ }^{a}$ (SD) } \\
\hline $\mathrm{KOOS}_{4}$ & $55.15(10.84)$ & $55.34(12.88)$ \\
\hline KOOS symptoms/stiffness & $52.50(16.76)$ & $51.79(17.52)$ \\
\hline KOOS pain & $64.72(15.33)$ & $58.33(17.67)$ \\
\hline KOOS function (daily living) & $68.38(15.90)$ & $67.50(15.97)$ \\
\hline KOOS quality of life & $35.00(14.49)$ & $43.75(12.15)$ \\
\hline \multicolumn{3}{|l|}{ Quality of Life, mean (SD) } \\
\hline EQ-5D Index & $0.45(0.37)$ & $0.49(0.27)$ \\
\hline EQ-5D VAS & $73.50(20.15)$ & $64.50(15.71)$ \\
\hline \multicolumn{3}{|l|}{ Psychology, mean (SD) } \\
\hline Pain, Enjoyment, General Activity Scale & $6.33(2.26)$ & $5.33(2.05)$ \\
\hline Patient Health Questionnaire 4 & $2.20(3.91)$ & $3.60(3.95)$ \\
\hline \multicolumn{3}{|l|}{ Functional Assessment, mean (SD) } \\
\hline Timed $10 \mathrm{~m}$ walked test (sec) & $5.62(1.06)$ & $7.00(1.64)$ \\
\hline Time up-and-go test (sec) & $10.27(2.51)$ & $12.83(2.11)$ \\
\hline 30s chair stand test (count) & $9.30(3.53)$ & $6.90(3.51)$ \\
\hline 4 stairs climb test (sec) & $8.39(4.00)$ & $11.94(6.20)$ \\
\hline
\end{tabular}

${ }^{a}$ for bilateral knee $\mathrm{OA}$, the index/most severe joint was used

time, recognizing how exercise can help patients cope better with these changes.

"It's good to learn about the different exercises techniques and how to improvise them" (P002).

"Knee condition seems to improve but don't think it will go back to normal" (P019).

Secondly, for nutrition and dietetic components, patients felt that while most of the dietary information was not new to them, the emphasis on "mindful eating" was particularly useful where patients were taught to actively monitor their dietary intake instead of taking a passive stance.

Thirdly, for the psychology sessions, there was an initial reluctance due to social stigma that psychology intervention was associated with mental illness such as depression. However, the patients felt that it was very beneficial upon completion of the program. Enhancing self-management was a common theme that many patients felt would help them maintain their improvement. 


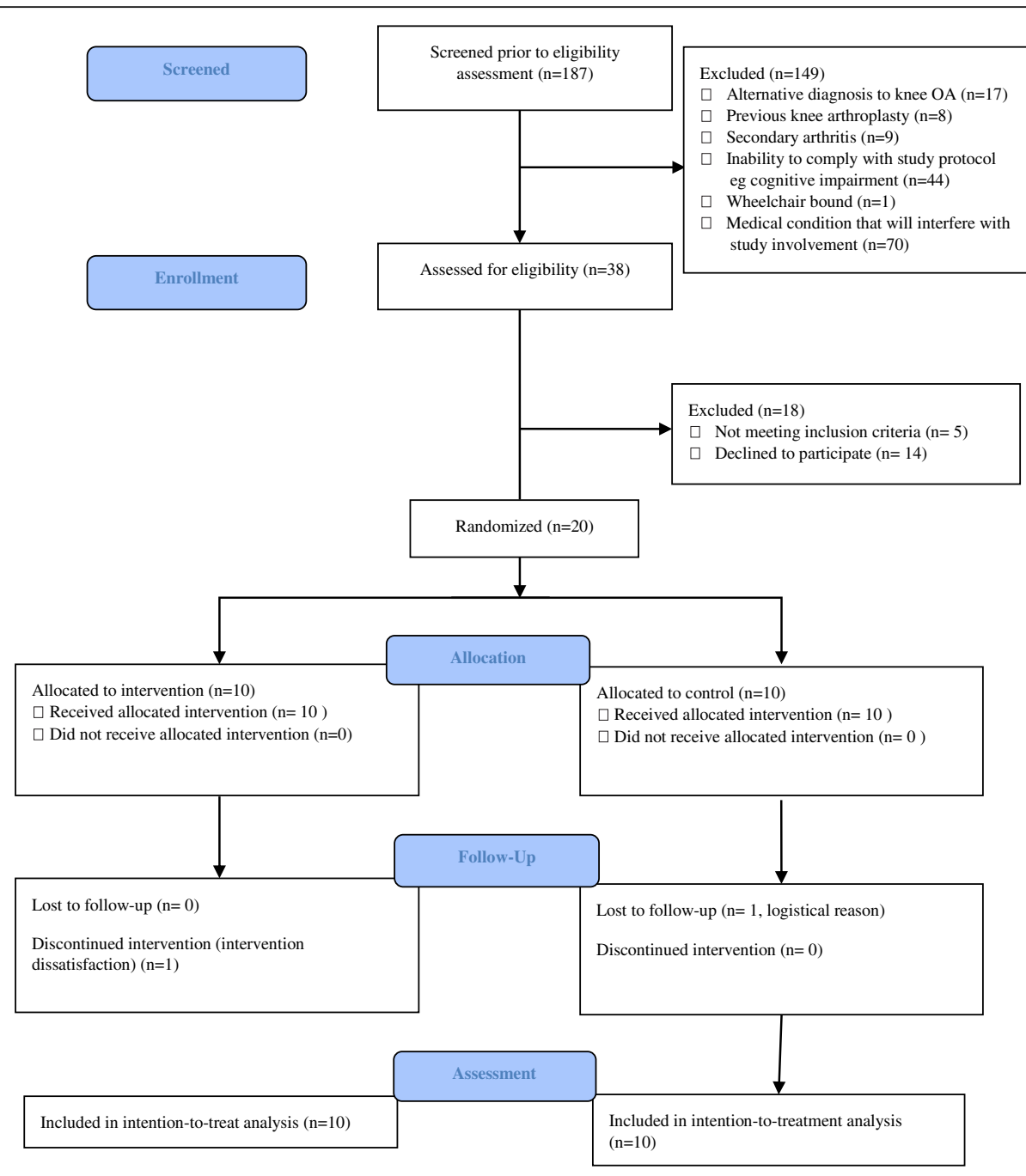

Fig. 1 Flow diagram

"It serves as a reminder to direct our mindsets to a positive direction" (P013).

Fourthly, in terms of general feedback received, there was very positive feedback for an intact group concept where patients were kept together throughout the 12week program instead of having patients constantly moving in and out of the program. They felt that the community setting was welcoming and many of the patients looked forward to the sessions. Some patients shared information about how they wanted to keep in touch even after the program concluded. Many patients expressed some form of positive peer pressure from fellow patients.

"Happy to see the same faces.... making friends" (P012).

"You feel motivated to be even better when you see others improved over time" (P002).
"Everyone is very caring and accommodating. Feels warm coming to the program" (P013).

The second focus of the process evaluation and interview was the feasibility of a larger trial. All the patients in participating in the study did not express any regret participating however reporting significant difficulty understanding certain psychological outcome measures (AAQ-II [47], CPAQ-8 [48], GIC [49]) and thus the majority of these outcome measures were not able to be completed by the patients. Several patients expressed that they would recommend their friends suffering from similar conditions to participate in the program.

\section{Discussion}

The CONNACT model of care is a complex intervention consisting of several different components interacting with each other. The Medical Research Council guidance on developing and evaluating complex 
Table 7 12-weeks Outcome Measures

\begin{tabular}{|c|c|c|c|}
\hline Outcome Measure & Improvement in Control (Median, IQR) & Improvement in Intervention (Median, IQR) & $p$-value \\
\hline \multicolumn{4}{|l|}{ KOOS score } \\
\hline $\mathrm{KOOS}_{4}$ & $9.46(30.28)$ & $21.38(21.38)$ & 0.34 \\
\hline KOOS symptoms/stiffness & $5.36(43.75)$ & $28.57(39.29)$ & 0.28 \\
\hline KOOS pain & $13.89(33.34)$ & $25.00(8.33)$ & 0.39 \\
\hline KOOS function (daily living) & $10.30(34.19)$ & $22.88(13.24)$ & 0.63 \\
\hline KOOS quality of life & $12.50(32.81)$ & $25.00(25.00)$ & 0.41 \\
\hline \multicolumn{4}{|l|}{ Quality of Life } \\
\hline EQ-5D Index & $0.46(0.67)$ & $0.34(0.31)$ & 0.56 \\
\hline EQ-5D VAS & $10.00(30.00)$ & $15.00(20.00)$ & 0.47 \\
\hline \multicolumn{4}{|l|}{ Psychology } \\
\hline PEG & $-1.50(6.00)$ & $-2.33(2.33)$ & 0.89 \\
\hline PHQ-4 & $0.00(1.75)$ & $0.00(4.00)$ & 0.18 \\
\hline Weight & $1.80(1.97)$ & $-0.30(1.90)$ & 0.59 \\
\hline \multicolumn{4}{|l|}{ Functional Assessment } \\
\hline Timed $10 \mathrm{~m}$ walked test (sec) & $0.44(1.63)$ & $0.29(1.30)$ & 0.45 \\
\hline Time up-and-go test (sec) & $1.23(4.31)$ & $0.40(1.61)$ & 0.20 \\
\hline 30s chair stand test (repetitions) & $2.00(1.50)$ & $3.00(2.00)$ & 0.23 \\
\hline 4 stairs climb test (sec) & $0.62(8.54)$ & 1.59 (3.06) & 0.42 \\
\hline
\end{tabular}

interventions recommends a feasibility and piloting phase at the start prior to a full study [59]. The primary aim of the pilot study was to determine the feasibility of a full RCT through pre-defined progression criteria. The secondary aim was to optimize the intervention and study design through a process evaluation in preparation for a full RCT. Results from the pilot affirmed the feasibility of the study to progress to a full RCT. Secondly, results from the process evaluation through the interviews informed trial design methodology and intervention optimization.

\section{Feasibility of a full RCT}

Based on the proposed progression criteria, all the areas of the pilot were ready to proceed with a full RCT except the recruitment aspect where only 20 patients were recruited for the study. Avery et al. proposed solutions in the event of insufficient recruitment including exploring screening logs to determine if insufficient participants were approached, passed eligibility criteria or agreed to randomization. After a throughout review of our screening logs and recruitment process, the primary reason identified was insufficient patients were screened and directed to the recruitment clinic during the recruitment period. Based on the recruitment rate from the pilot, a wider net for screening of all referrals and additional recruitment clinics are planned during subsequent recruitment cycles for the sample size calculations to be fulfilled within the duration of the study.

The pilot study results suggested that patients who underwent the intervention were more likely to have a better knee function score, better quality of life, have less anxiety and depression, lose weight and exhibit a positive dietary change compared to control arm patients.

Table 8 Progression Criteria

\begin{tabular}{lll}
\hline Domain & Results & Readiness for Progression \\
\hline Patient Recruitment & 20 patients & Do not proceed with RCT unless problem can be solved \\
Patient Retention & $85 \%$ & Proceed with RCT \\
Intervention Completion & $80 \%$ & Proceed with RCT \\
Outcome measure acceptance & $100 \%$ & Proceed with RCT \\
Improvement in function and/or quality of life (Intervention arm) & $88.8 \%$ & Proceed with RCT \\
Serious Adverse events & 0 & Proceed with RCT \\
\hline
\end{tabular}


Although none of the results reached statistical significance potentially owing to low patient numbers, these results are promising.

Compared to taking reference values from other studies, results from this pilot study including the mean values and standard deviations of the primary outcome, $\mathrm{KOOS}_{4}$ will be used for a more representative power analysis to calculate the required sample size for the main RCT.

\section{Proposed changes to intervention}

Results from the qualitative study informed changes to the intervention protocol that could potentially enhance its effectiveness. The number of exercise sessions will be increased from 6 to 8 sessions in line with international programs which can utilize up to 24 sessions over a 12 week period [19]. The dietetic syllabus will be modified to focus more on "mindful eating" and practical examples on how to make a sustainable diet change compared to simply giving patients a dietetic lecture on the relative health benefits of different food groups. The groupbased intervention format will be retained. Group-based interventions have been shown to be more effective compared to individual interventions [36]. A flexible post-intervention program will be developed for patients who would like continue to exercise together in a group and social network platforms e.g. Whatsapp group chats or Facebook groups will also be utilized to facilitate patient group interaction throughout and postintervention. Keeping a group-based program does pose logistical challenges. In order to overcome this, recruitment for the main trial will be done in cycles to group patients into classes and retain this key element.

In line with the overall thrust of enhancing patient self-management, patient activation is a key concept that will be included as part of the intervention. Patient activation is defined as an individual's propensity to engage in adaptive health behaviour that may lead to improved outcomes. Activation levels is measured by the Patient Activated Measure (PAM) [60], a validated questionnaire that looks at knowledge, skills and confidence in managing health. There has been increasing evidence in the literature that high PAM scores have been associated with more satisfaction with healthcare services, better self-management behaviour and improved health outcome $[61,62]$. In addition to PAM being added in as an outcome measure, PAM levels of less than 3 will also serve as an independent eligibility criterion for psychological intervention. Several key areas has been identified when including activation as part of any intervention, including physician-patient relationships, self-management, facilitating behaviour change and tailoring interventions according to activation levels [63]. Based on these principles, a greater emphasis on patient activation will also be included into the psychological intervention.

A recent Cochrane review on exercise interventions and patient beliefs for people with hip or knee OA revealed that many patients are confused about the cause of their pain and are unsure about what steps they should take to manage their pain generally resulting in activity avoidance for fear of causing harm [64]. Evidence has shown the potential that proper education and behaviour modification has in producing long lasting sustainable positive effects in OA programs [65]. Proposed topics for the education sessions are based on areas of patients' knowledge deficiencies identified by the Cochrane review. These topics include the following.

1. Pathophysiology behind OA

2. Flare management - what causes flares and how to deal with them

3. Treatment options and their relative effectiveness, pros and cons

"Expert patients" is a relatively novel concept where patients who have successfully completed the program are invited to share their experiences with the incoming batch of participants. Expert patients have previously been included in similar programs [28]. "Expert patients" will be incorporated in the main trial intervention as part of the educational component as volunteers. They will be recruited from previous cycles of patients who have successfully completed and benefited from the intervention.

\section{Proposed changes to methodology}

There were several proposed modifications to the choice of outcome measures both based on the process evaluation and additional literature review after review of the pilot study results. Firstly, some of the psychological questionnaires (AAQ-II [47], CPAQ-8 [48], GIC [49]) were removed as all the patients had difficulty understanding resulting in completion difficulty. Other outcome measures such as the PAM, Global Perceived Effect (GPE) [49], Patient Acceptable Symptom State (PASS) and treatment failure [66] which are sensitive but simple questionnaires will be included for the subsequent RCT in place of the excluded questionnaires as these outcome measures have previously been used in musculoskeletal conditions of the knee [67]. The overall respondent burden would be reduced.

Compliance to exercises is a key outcome measure and a potential confounder when interpreting trial results that was not measured in the initial pilot. In the current literature, there is a lack of validated questionnaire that reliably measures exercises compliance or adherence [68]. Compliance can be assessed in 2 different 
ways, either through patient reported measures or clinician assessment. For the main trial, a comprehensive assessment for compliance was deemed to be crucial due to nature of intervention where patient participation played a critical role. For patient reported outcomes, a simple questionnaire will be developed focusing on exercises compliance and reasons for non-compliance that will be administered to the intervention arm patients at 3 months, 6 months and 12 months. For clinician assessment, the Sports Injury Rehabilitation Adherence Scale (SIRAS) [69] is a validated tool for compliance assessment.

\section{Strengths}

This paper highlights a comprehensive approach of a feasibility study using a pilot randomized trial prior to an RCT for a complex intervention. Firstly, progression criteria based on established guidelines was developed prior to the conduct of the pilot study as an objective benchmark to decide if a full RCT was feasible at that point in time. These proposed progression criteria can be adopted and evaluated by other pilot studies looking at similar interventions for musculoskeletal conditions.

Secondly, a process evaluation guided by the MRC guidelines [58] was embedded within the pilot study through qualitative methods focusing on intervention optimization and feasibility. This allowed for informed modifications to be made to both the intervention and study methodology to give the subsequent RCT every chance of success.

\section{Limitation}

We were only able to recruit 20 patients instead of the targeted sample size of 30 patients. While sample sizes for pilot studies are less critical in ensuring adequate power, this highlighted a key area moving forward for our main RCT. Recruitment was one of the key elements described in the progression criteria. Our patient recruitment strategy was critically evaluated and key changes will be made for the main trial.

There were significant differences between the control and intervention population group in terms of gender distribution and mean age. The mean age in the control arm was significant younger and had more males compared to the intervention arm. In general, there were significantly more females compared to males in both the intervention and control arm. This could be a result of the small sample size. This issue will likely be addressed during the main RCT where a much large sample size will be targeted and use of stratified randomization to control for gender.

\section{Conclusion}

This pilot has demonstrated the feasibility of a full RCT investigating the potential effectiveness of the CONNACT model of care for knee OA using pre-defined progression criteria and process evaluation. Results from the qualitative study were used to modify and improve the intervention content, delivery model and study design for a large effectiveness-implementation hybrid RCT that is currently underway. This main trial includes 1-year follow-up, economic evaluation and process evaluation using the MRC guidelines [58], the RE-AIM (Reach, Effectiveness, Adoption, Implementation, Maintenance) implementation and evaluation framework [7] and the Global Alliance for MSK Health (GMUSC) framework [26] to guide large scale implementation.

\section{Abbreviations}

CONNACT: Collaborative Model of Care between Orthopaedics and Allied Health Professionals Trial; MSK: Musculoskeletal; OA: Osteoarthritis; RCT: Randomized Controlled Trial; NICE: National Institute of Health and Care Excellence; ACSM: American College of Sports Medicine; NEMEX: Neuromuscular Exercise; OARSI: Osteoarthritis Research Society International; KOOS: Knee Injury and Osteoarthritis Outcome Score; EQ-5D5L: EuroQol 5 dimensions 5 level; BMI: Body Mass Index; PHQ-4: Patient Health Questionnaire 4; PEG: Pain, Enjoyment, General Activity Scale; ACT: Acceptance and Commitment Therapy; AAQ-II: Acceptance and Action Questionnaire 2; CPAQ-8: Chronic Pain Acceptance Questionnaire 8; GIC: Global Impression of Change; FFQ: Food Frequency Questionnaire; ITT: Intention-to-treatPAMPatient Activation Measure; GPE: Global Perceived Effect; PASS: Patient Acceptable Symptom State; SIRAS: Sports Injury Rehabilitation Adherence Scale; MoC: Model of Care; IQR: Interquartile range; SD: Standard Deviation

\section{Acknowledgements}

NA

\section{Authors' contributions}

BYT was the lead investigator involved in the study design, patient recruitment, data analysis and manuscript preparation. BTKD and MJP were involved in the patient recruitment and data collection. STS, JT and JC were the senior authors providing input in the study design, data analysis and interpretation. All the authors were involved in the preparation of the manuscript and have approved the final manuscript.

\section{Funding}

Ng Teng Fong Health Innovation Program Grant \$200,000. The funding body was not involved in the study design, data collection, analysis or interpretation of the data.

\section{Availability of data and materials}

The datasets used and/or analysed during the current study are available from the corresponding author on reasonable request.

\section{Ethics approval and consent to participate}

Ethics approval was obtained through the Institution Review Board prior to the conduct of the study (National Healthcare Group Domain Specific Review Board Ref: 2018/00408). Written consent was obtained from the study participants.

\section{Consent for publication}

NA

\section{Competing interests}

The authors declare that they have no competing interest.

\section{Author details}

${ }^{1}$ Department of Orthopaedic Surgery, Woodlands Health Campus, National Healthcare Group, Singapore, Singapore. 'Lee Kong Chian School of Medicine, Nanyang Technological University, Singapore, Singapore. ${ }^{3}$ Ministry of Health Holdings, Singapore, Singapore. ${ }^{4}$ Health Services Outcome Research, National Healthcare Group, Singapore, Singapore. ${ }^{5}$ Research Unit 
for Musculoskeletal Function and Physiotherapy, Department of Sports Science and Clinical Biomechanics, University of Southern Denmark, Odense M, Denmark. ${ }^{6}$ Department of Physiotherapy and Occupational Therapy, Næstved-Slagelse-Ringsted Hospitals, Slagelse, Denmark. ${ }^{7}$ Singapore General Hospital, Singapore, Singapore.

Received: 20 January 2020 Accepted: 26 August 2020

Published online: 04 September 2020

\section{References}

1. Cross M, Smith E, Hoy D, Nolte S, Ackerman I, Fransen M, et al. The global burden of hip and knee osteoarthritis: estimates from the global burden of disease 2010 study. Ann Rheum Dis. 2014;73(7):1323-30.

2. McGrory B, Weber K, Lynott JA, Richmond JC, Davis CM 3rd, Yates A Jr, et al. The American Academy of Orthopaedic surgeons evidence-based clinical practice guideline on surgical Management of Osteoarthritis of the knee. $J$ Bone Joint Surg Am. 2016;98(8):688-92.

3. McAlindon TE, Bannuru RR, Sullivan MC, Arden NK, Berenbaum F, BiermaZeinstra SM, et al. OARSI guidelines for the non-surgical management of knee osteoarthritis. Osteoarthr Cartil. 2014;22(3):363-88.

4. Australian Institute for Health and Welfare. Use of health services for arthritis and osteoporosis, in Arthritis Series no. 14. Cat. no. PHE 130. Canberra: AlHW; 2010

5. Basedow M, Esterman A. Assessing appropriateness of osteoarthritis care using quality indicators: a systematic review. J Eval Clin Pract. 2015;21(5): 782-9.

6. Hagen KB, Smedslund G, Osteras N, Jamtvedt G. Quality of communitybased osteoarthritis care: a systematic review and meta-analysis. Arthritis Care Res. 2016;68(10):1443-52.

7. Allen KD, Choong PF, Davis AM, Dowsey MM, Dziedzic KS, Emery C, et al. Osteoarthritis: models for appropriate care across the disease continuum. Best Pract Res Clin Rheumatol. 2016;30(3):503-35.

8. Kurtz S, Ong K, Lau E, Mowat F, Halpern M. Projections of primary and revision hip and knee arthroplasty in the United States from 2005 to 2030. J Bone Joint Surg Am. 2007;89(4):780-5.

9. Ackerman IN, Bohensky MA, Zomer E, Tacey M, Gorelik A, Brand CA, et al. The projected burden of primary total knee and hip replacement for osteoarthritis in Australia to the year 2030. BMC Musculoskelet Disord. 2019; 20(1):90.

10. Molloy IB, Martin BI, Moschetti WE, Jevsevar DS. Effects of the length of stay on the cost of Total knee and Total hip Arthroplasty from 2002 to 2013. J Bone Joint Surg Am. 2017;99(5):402-7.

11. Mulcahy H, Chew FS. Current concepts in knee replacement: complications. AJR Am J Roentgenol. 2014;202(1):W76-86.

12. Kurtz SM, Lau E, Ong K, Zhao K, Kelly M, Bozic KJ. Future young patient demand for primary and revision joint replacement: national projections from 2010 to 2030. Clin Orthop Relat Res. 2009;467(10):2606-12.

13. Choi YJ, Ra HJ. Patient satisfaction after Total knee Arthroplasty. Knee Surg Relat Res. 2016;28(1):1-15.

14. Beswick AD, Wylde V, Gooberman-Hill R, Blom A, Dieppe P. What proportion of patients report long-term pain after total hip or knee replacement for osteoarthritis? A systematic review of prospective studies in unselected patients. BMJ Open. 2012;2(1):e000435.

15. Miller GD, Rejeski WJ, Williamson JD, Morgan T, Sevick MA, Loeser RF, et al. The arthritis, diet and activity promotion trial (ADAPT): design, rationale, and baseline results. Control Clin Trials. 2003;24(4):462-80.

16. Messier SP, Mihalko SL, Legault C, Miller GD, Nicklas BJ, DeVita P, et al. Effects of intensive diet and exercise on knee joint loads, inflammation, and clinical outcomes among overweight and obese adults with knee osteoarthritis: the IDEA randomized clinical trial. Jama. 2013;310(12):1263-73.

17. Bennell KL, Ahamed Y, Jull G, Bryant C, Hunt MA, Forbes AB, et al. Physical therapist-delivered pain coping skills training and exercise for knee osteoarthritis: randomized controlled trial. Arthritis Care Res. 2016;68(5):590602.

18. Marconcin P, Espanha M, Teles J, Bento P, Campos P, André R, et al. A randomized controlled trial of a combined self-management and exercise intervention for elderly people with osteoarthritis of the knee: the PLE2NO program. Clin Rehabil. 2018;32(2):223-32.

19. Skou ST, Rasmussen S, Laursen MB, Rathleff MS, Arendt-Nielsen L, Simonsen $\mathrm{O}$, et al. The efficacy of 12 weeks non-surgical treatment for patients not eligible for total knee replacement: a randomized controlled trial with 1 year follow-up. Osteoarthr Cartil. 2015;23(9):1465-75.

20. Eldridge SM, Lancaster GA, Campbell MJ, Thabane L, Hopewell S, Coleman $\mathrm{CL}$, et al. Defining Feasibility and Pilot Studies in Preparation for Randomised Controlled Trials: Development of a Conceptual Framework. PLoS One. 2016;11(3):e0150205.

21. Allen KD, Bierma-Zeinstra SM, Foster NE, Golightly YM, Hawker G. OARSI clinical trials recommendations: design and conduct of implementation trials of interventions for osteoarthritis. Osteoarthr Cartil. 2015;23(5):826-38.

22. Eldridge $\mathrm{SM}$, Chan $\mathrm{CL}$, Campbell MJ, Bond CM, Hopewell S, Thabane L, et al. CONSORT 2010 statement: extension to randomised pilot and feasibility trials. Pilot Feasibility Studies. 2016;2:64.

23. National Institute for Health and Care Excellence (NICE) Guideline 2014 Osteoarthritis: care and management

24. Kellgren JH, Lawrence JS. Radiological assessment of osteo-arthrosis. Ann Rheum Dis. 1957;16(4):494-502.

25. Roos EM, Lohmander LS. The knee injury and osteoarthritis outcome score (KOOS): from joint injury to osteoarthritis. Health Qual Life Outcomes. 2003; 1:64.

26. Briggs AM, Jordan JE, Jennings M, Speerin R, Bragge P, Chua J, et al. Supporting the evaluation and implementation of musculoskeletal models of care: a globally informed framework for judging readiness and success. Arthritis Care Res. 2017;69(4):567-77.

27. Sanders JO, Murray J, Gross L. Non-arthroplasty treatment of osteoarthritis of the knee. J Am Acad Orthop Surg. 2014;22(4):256-60.

28. Skou ST, Roos EM. Good life with osteoArthritis in Denmark (GLA:D): evidence-based education and supervised neuromuscular exercise delivered by certified physiotherapists nationwide. BMC Musculoskelet Disord. 2017; 18(1):72.

29. NSW Agency for Clinical Innovation. Musculoskeletal Network. Osteoarthritis Chronic Care Program Model of Care. https://www.aci.health.nsw.gov.au/ resources/musculoskeletal/osteoarthritis_chronic_care_program/ osteoarthritis-chronic-care-program.

30. Grover A, Joshi A. An overview of chronic disease models: a systematic literature review. Global J Health Sci. 2014;7(2):210-27.

31. Sharma A, Kudesia P, Shi Q, Gandhi R. Anxiety and depression in patients with osteoarthritis: impact and management challenges. Open Access Rheumatol. 2016:8:103-13.

32. Sharma L, Cahue S, Song J, Hayes K, Pai Y-C, Dunlop D. Physical functioning over three years in knee osteoarthritis: role of psychosocial, local mechanical, and neuromuscular factors. Arthritis Rheum. 2003;48(12):3359-70.

33. Kroenke K, Spitzer RL, Williams JB, Lowe B. An ultra-brief screening scale for anxiety and depression: the PHQ-4. Psychosomatics. 2009;50(6):613-21.

34. Krebs EE, Lorenz KA, Bair MJ, Damush TM, Wu J, Sutherland JM, et al. Development and initial validation of the PEG, a three-item scale assessing pain intensity and interference. J Gen Intern Med. 2009;24(6):733-8.

35. Cleeland CS, Ryan KM. Pain assessment: global use of the brief pain inventory. Ann Acad Med Singap. 1994;23(2):129-38.

36. Burke S, Carron A, Eys M, Ntoumanis N, Estabrooks P. Group versus individual approach? A meta-analysis of the effectiveness of interventions to promote physical activity. Sport Exer Psychol Rev. 2005;2(1):13.

37. American College of Sports Medicine, Riebe D, Ehrman JK, Liguori G, Magal M. ACSM's guidelines for exercise testing and prescription (Tenth edition.) Philadelphia: Wolters Kluwer; 2018.

38. National Institute for Health and Care Excellence (NICE) Guideline 2014. Weight management: lifestyle services for overweight or obese adults.

39. Hayes SCSK, Wilson KG. Acceptance and commitment therapy (an experiential approach to behavior change): New York: a division of Guildford publications Inc; 1999.

40. Yang S-Y, McCracken L. Acceptance and commitment therapy for chronic pain. J Clin Outcomes Manag. 2014;21:134-44.

41. Hsu WC, Araneta MRG, Kanaya AM, Chiang JL, Fujimoto W. BMI cut points to identify at-risk Asian Americans for type 2 diabetes screening. Diabetes Care. 2015;38(1):150

42. Xie F, Li SC, Roos EM, Fong KY, Lo NN, Yeo SJ, et al. Cross-cultural adaptation and validation of Singapore English and Chinese versions of the knee injury and osteoarthritis outcome score (KOOS) in Asians with knee osteoarthritis in Singapore. Osteoarthr Cartil. 2006;14(11):1098-103.

43. Charlson ME, Pompei P, Ales KL, MacKenzie CR. A new method of classifying prognostic comorbidity in longitudinal studies: development and validation. J Chronic Dis. 1987:40(5):373-83. 
44. Mahoney Fl, Barthel DW. Functional evaluation: The BARTHEL index. Md State Med J. 1965;14:61-5.

45. The EuroQol Group. EuroQol--a new facility for the measurement of healthrelated quality of life. Health policy. 1990;16(3):199-208.

46. Neelakantan N, Whitton C, Seah S, Koh H, Rebello SA, Lim JY, et al. Development of a Semi-Quantitative Food Frequency Questionnaire to Assess the Dietary Intake of a Multi-Ethnic Urban Asian Population. Nutrients. 2016;8(9):528.

47. Bond FW, Hayes SC, Baer RA, Carpenter KM, Guenole N, Orcutt HK, et al. Preliminary psychometric properties of the acceptance and action questionnaire-ll: a revised measure of psychological inflexibility and experiential avoidance. Behav Ther. 2011;42(4):676-88.

48. Fish RA, McGuire B, Hogan M, Morrison TG, Stewart I. Validation of the chronic pain acceptance questionnaire (CPAQ) in an internet sample and development and preliminary validation of the CPAQ-8. Pain. 2010;149(3):435-43.

49. Scott W, McCracken LM. Patients' impression of change following treatment for chronic pain: global, specific, a single dimension, or many? J Pain. 2015; 16(6):518-26.

50. Luo N, Wang P, Thumboo J, Lim YW, Vrijhoef HJ. Valuation of EQ-5D-3L health states in Singapore: modeling of time trade-off values for 80 empirically observed health states. PharmacoEconomics. 2014;32(5):495-507.

51. Dobson F, Hinman RS, Roos EM, Abbott JH, Stratford P, Davis AM, et al. OARSI recommended performance-based tests to assess physical function in people diagnosed with hip or knee osteoarthritis. Osteoarthr Cartil. 2013; 21(8):1042-52

52. Avery KNL, Williamson PR, Gamble C, O'Connell Francischetto E, Metcalfe C, Davidson $\mathrm{P}$, et al. Informing efficient randomised controlled trials: exploration of challenges in developing progression criteria for internal pilot studies. BMJ Open. 2017;7(2):e013537.

53. Asada F, Nomura T, Fukuzumi T, Aota E, Ito K, Tagami M, et al. Effect of exercise education on promoting daily physical activity in Japanese workers: A randomized controlled trial. Physiotherapy (United Kingdom). 2011; 97(SUPPL. 1):eS88.

54. Whitehead AL, Julious SA, Cooper CL, Campbell MJ. Estimating the sample size for a pilot randomised trial to minimise the overall trial sample size for the external pilot and main trial for a continuous outcome variable. Stat Methods Med Res. 2016;25(3):1057-73.

55. Juhl C, Christensen R, Roos EM, Zhang W, Lund H. Impact of exercise type and dose on pain and disability in knee osteoarthritis: a systematic review and meta-regression analysis of randomized controlled trials. Arthritis Rheum. 2014;66(3):622-36.

56. Harris PA, Taylor R, Minor BL, Elliott V, Fernandez M, O'Neal L, et al. The REDCap consortium: Building an international community of software platform partners. J Biomed Inform. 2019;95:103208.

57. Harris PA, Taylor R, Thielke R, Payne J, Gonzalez N, Conde JG. Research electronic data capture (REDCap)--a metadata-driven methodology and workflow process for providing translational research informatics support. J Biomed Inform. 2009;42(2):377-81.

58. Moore GF, Audrey S, Barker M, Bond L, Bonell C, Hardeman W, et al. Process evaluation of complex interventions: Medical Research Council guidance. BMJ (Clinical research ed). 2015;350:h1258.

59. Craig P, Dieppe P, Macintyre S, Michie S, Nazareth I, Petticrew M. Developing and evaluating complex interventions: the new Medical Research Council guidance. BMJ (Clinical research ed). 2008;337:a1655.

60. Hibbard JH, Mahoney ER, Stockard J, Tusler M. Development and testing of a short form of the patient activation measure. Health Serv Res. 2005;40(6 Pt 1):1918-30.

61. Hibbard $\mathrm{JH}$, Greene J. What the evidence shows about patient activation: better health outcomes and care experiences; fewer data on costs. Health Affairs (Project Hope). 2013;32(2):207-14.

62. Hibbard JH, Greene J, Tusler M. Improving the outcomes of disease management by tailoring care to the patient's level of activation. Am J Manag Care. 2009;15(6):353-60

63. Ngooi B. What are the crucial components of patient activation interventions? Biomed J Sci Tech Res. 2017;1(2);2017. BJSTR. MS.ID.000215.

64. Hurley M, Dickson $\mathrm{K}$, Hallett R, Grant R, Hauari H, Walsh N, et al. Exercise interventions and patient beliefs for people with hip, knee or hip and knee osteoarthritis: a mixed methods review. Cochrane Database Syst Rev. 2018;4: Cd010842.

65. Williamson W, Kluzek S, Roberts N, Richards J, Arden N, Leeson P, et al. Behavioural physical activity interventions in participants with lower-limb osteoarthritis: a systematic review with meta-analysis. BMJ Open. 2015;5(8): e007642.

66. Dougados M, Moore A, Yu S, Gitton X. Evaluation of the patient acceptable symptom state in a pooled analysis of two multicentre, randomised, double-blind, placebo-controlled studies evaluating lumiracoxib and celecoxib in patients with osteoarthritis. Arthritis Res Ther. 2007:9:R11.

67. Skou ST, Lind M, Hölmich P, Jensen HP, Jensen C, Afzal M, et al. Study protocol for a randomised controlled trial of meniscal surgery compared with exercise and patient education for treatment of meniscal tears in young adults. BMJ Open. 2017;7(8):e017436 e.

68. McLean S, Holden MA, Potia T, Gee M, Mallett R, Bhanbhro S, et al. Quality and acceptability of measures of exercise adherence in musculoskeletal settings: a systematic review. Rheumatology. 2017:56(3):426-38.

69. Kolt GS, Brewer BW, Pizzari T, Schoo AMM, Garrett N. The sport injury rehabilitation adherence scale: a reliable scale for use in clinical physiotherapy. Physiotherapy. 2007;93(1):17-22.

\section{Publisher's Note}

Springer Nature remains neutral with regard to jurisdictional claims in published maps and institutional affiliations.
Ready to submit your research? Choose BMC and benefit from:

- fast, convenient online submission

- thorough peer review by experienced researchers in your field

- rapid publication on acceptance

- support for research data, including large and complex data types

- gold Open Access which fosters wider collaboration and increased citations

- maximum visibility for your research: over $100 \mathrm{M}$ website views per year

At BMC, research is always in progress.

Learn more biomedcentral.com/submissions 